\title{
BDKRB2 Gene
}

National Cancer Institute

\section{Source}

National Cancer Institute. BDKRB2 Gene. NCI Thesaurus. Code C24264.

This gene is involved in the contractile regulation of vasculature and smooth muscle cells.

Additionally, this plays a role in edema and pain stimulation. 